its action on the vomiting centre, a hundred or more are given in congh mixtures and preparations. Enetics are comparatively rarely required, but our chronic bronchitics demand a constant supply of expectorants. It is true that the present 1 in 50 solution is by no means inconvenient for dispensing purposes, but the difficulty with respect to the name still remains. Only the other day I wrote a prescription for a mix ture containing half a drachm of "injectio apomorphinæ hypodermica," and the chemist sent the apomorphine in one bottle labeled "The Hypodermic Injection," and the syrup of tar and water in another labeled "The Cough Linctus." Such mistakes are of constant occurrence, and are a perpetual source of annoy ance and inconvenience. The "solution of apomorphine"-which, it is to be trusted, will be made with hydrochloric acid and not with camphor water-was suggested to get rid of this anomaly, and the strength ( 1 per cent.) was adopted to bring it into conformity with the other official liquors. The object would not be attained by diluting the present official solution, for the difficulty of the name would not be overcome, and the liquor is intended for dispensing and as an ingredient of cough medicines, and not for use by the physician as a hypodermic injection. I would venture to remind you that whilst suggestions were requested respecting the introduction of new drugs and new preparations, it was distinctly understood that no interference with the existing Pharmacopoia could be entertained until the next decennial revision in 1895.

Whilst on the subject I should be glad if I might be allowed an opportunity of answering another objection which has been raised to the list proposed by the Royal College of Physicians. It has been said that the nomenclature adopted is destitute of scientific accuracy. This is not so, for the terminal " $\mathrm{e}$ " has been employed in the case of all alkaloids and drugs possessing alkaloidal properties, whilst it is has been omitted in the case of substances not included in this category. For example, "hyoscine" and "apomorphine" are in conformity with "atropine" and "morphine," whilst lanolin and pancreatin, not being alkaloids, have been deprived of the terminal letter. With respect to antipyrine, some doubt existed as to its exact chemical composition, and it was given the benefit of the doubt, regard being had to the fact that it is to be introduced under some name "not involving the acceptance of any theory respecting its mode of action." iIt will be noted that in the report nitro-glycerin is spelt without the final "e," although the nomenclature differs "from that adopted in the body of the work both for nitroglycerine and glycerine. The list of drugs recommended is, as you very justly remark, modest, and not likely to give aise to much discussion; but I must confess that, personally, I do not think that it is very satisfactory. I am sorry that the opportunity should have been lost of extending our scanty list of flavouring agents, and it is difficult to understand why pancreatin should have been recommended for insertion, whilst the far more popular extract of malt is omitted. Under what name antipyrine will ultimately be adopted is not very clear. The chemical term "dimethyloxychinizine" is obviously too long for everyday use, whilst an objection has been raised to the contracted form, "dioxychinine."

I am, sirs, yours truly,

Weymouth-street, W., May 19th, 1890.

$$
\text { William MURRell, M.D. }
$$

\section{THE TREATMENT OF EPILEPSY BY BIBORATE}

$$
\text { OF SODA. }
$$

To the Editors of THE LANCET.

SIRs,-I can fully endorse the statements of Drs. Risien Russell and James Taylor in their interesting paper, which appeared in THE LANCET of the $17 \mathrm{th}$ inst., with regard to the value of borax in the treatment of epilepsy, and I agree with them as to the necessity for omphasising this fact; for although here and there in medical iiterature it is recorded that fits have been cured by borax, the virtues of this remedy have for the most part been either ignored or under-estimated. Yet I think there can to no doubt that when the bromides, administered either alone or in conjunction with belladonna, fail to relieve convulsive seizures, biborate of soda is the most likely drug to be of service. And I would also point out that boracic acid, so far as I have tried it, appears to be quite as efficacious as its alkaline salt. Its value is strikingly illustrated by the following case, which was under my care at the Clinical Hospital about two years ago. It was that of a girl aged six years, who had been subject to fits for a few weeks, which the mother attributed to a fall on the head. The child attended as an out-patient for some time; but as the fits appeared to be uninfluenced by the administration of bromide of potassium, she was taken into the hospital, in order that the effects of treatment might be more accurately observed. During the first five days she took every four hours a mixture containing five grains of bromide of potassium and five minims of tincture of belladonna; but on each day she had from twelve to twenty attacks of general convulsions with loss of consciousness. The doses of bromide and belladonna were then increased to ten grains and seven minims respectively ; but as the frequency of the fits remained unaltered, she was ordered to take five grains of boric acid in water every four hours. During the next four days the number of fits fell to nine and ten daily, and when the dose of boric acid was increased to ten grains the improvement was still more marked; the fits ceased on the fifth day, and the child subsequently left the hospital completely cured. Since that time I have repeatedly prescribed boracic acid and borax, both for ordinary epilepsy and for the convulsions associated with the spastic hemiplegia of infancy, and as a rule with good results.

Asregards the mode of administration, it may be observed: (1) that both borax and boric acid are very soluble in glycerine; (2) that if we wish to prescribe borax alone, much glycerine should be excluded, for a mixture of pure neutral glycerine and pure borax is acid, owing to the presence of free boric acid; (3) that borax increases the solubility of boric acid to a considerable extent, so that it is often advantageous to give them in combination.

In conclusion, perhaps you will permit me to draw attention to the occasional value of borax or of boric acid in the treatment of coughs. A few grains of either drug will sometimes remove an obstinate cough in a young child, and especially if this be associated with an irritable condition of the fauces or pharynx. Boric acid is also highly spoken of by Atkinson ${ }^{1}$ as a remedy for puerperal fever ; Bükhaloff ${ }^{2}$ considers it a very effective substitute for quinine in the treatment of malarial fevers; and Peyrusson ${ }^{3}$ recommends large doses in cholera - I am, Sirs, yours truly,

Manchester, May 19th, 1890. JUDSON S. BURY.

\section{THE UNIVERSITY OF LONDON.}

\section{To the Editors of THE LANCET.}

SIRS,-Much discussion helps to clear the air, and enables us to put in order the pros and cons of a difficult question, so that each argument may be properly sifted and weighed. I would like to draw attention to some of the disputed points, and also to make a suggestion. The London University is not a local but an Inperial institution. Men come from all parts of the British Empire to receive its degrefs because of the prestige those degrees confer and their universal acceptance. Since its foundation the London University has moved on in a spirit of progress. Tampe: with that high standard, which has been its distinguishing feature, and you commence a retrograde movement the end of which you cannot see. The London medical student with his M.R.C.S. and L.R.C.P. qualifications has been as thoroughly trained as a Durham or Edinburgh graduate, but lacks the latter's privilege of being styled "Dr." Is it possible by any alterations in the method of training \&c. to raise the bulk of the London students to the standard of the London University? I doubt it. If you cannot raise the ordinary London student to the level of the present University, and you ought not to lower that University to him, you must fall back on the alternative scheme of a second University in London. What are the objections to an additional University in London? Are they insuperable? In Scotland, where the medical men number about one-half those in London, there are four Universities, each doing its own work without injury to the others. There can only be one University of London, but that is no reason why there should not be two or more Universities in London having different functions. Is it distance only which makes what is possible in Scotland impossible in London, or does the name "London" lie at

1 Practitioner, 1880. $\quad{ }^{2}$ Vrach, 1888. 3 Lyon Méd., 1884. 